\title{
Kelompok 6
}

- Nama Kelompok:

- Akbar ariq p 17190350

- Alfin M 17190407

- Iqbal Arya s 17190290 


\section{ANGKA INDEKS \\ Tidak tertimbang dan \\ tertimbang}




\section{Pengertian Angka Indeks}

Angka Indeks atau sering disebut indeks saja, pada dasarnya merupakan suatu angka yang dibuat sedemikian rupa sehingga dapat dipergunakan untuk melakukan perbandingan antara kegiatan yang sama dalam waktu yang berbeda. 


\section{Tujuan Pembuatan Angka Indeks}

- Untuk mengukur kuantitatif terjadinya perubahan dalam dua waktu yang berlainan.

- Untuk kepentingan pemantauan (monitoring) atau evaluasi. 


\section{Periode Waktu}

- Waktu Dasar (base period)

Periode yang dipakai sebagai dasar dalam membandingkan kegiatan tersebut. Waktu dasar biasanya dinyatakan dalam angka indeks, sebesar 100.

- Waktu Berjalan / Bersangkutan (current period) Periode yang dipakai yang sedang berjalan atau periode yang diperbandingkan dalam kegiatan tersebut. 


\section{Klasifikasi Angka Indeks}

- Indeks Harga \& Produksi Relatif Sederhana

- Indeks Rata-Rata Harga \& Produksi Relatif

- Indeks Agregatif 


\section{A. Indeks Harga dan Produksi Relatif Sederhana}

- Indeks Relatif Sederhana ialah indeks yang terdiri dari satu macam barang saja, baik untuk indeks produksi maupun indeks harga. 


\section{Rumus Indeks Harga Relatif Sederhana}

$$
I_{t, 0}=\frac{P t}{P o} \times 100 \%
$$

$$
\begin{aligned}
& I_{t, 0}=\text { indeks harga pada waktu } t \text { dengan waktu dasar } 0 \\
& P_{t}=\text { harga pada waktu } t \\
& P_{0}=\text { harga pada waktu } 0
\end{aligned}
$$

Rumus untuk menghitung indeks produksi sama seperti untuk menghitung indeks harga, hanya notasi $p$ diganti dengan notasi $q$. 


\section{B. Indeks Rata-Rata Harga \& Produksi Relatif}

- Indeks rata-rata harga relatif dinyatakan oleh persamaan berikut :

$$
\mathrm{t}, 0=\frac{1}{\mathrm{n}}\left[\sum \frac{\mathrm{p}_{\mathrm{t}}}{\mathrm{p}_{\mathrm{o}}} \times 100 \%\right]
$$

- Indeks rata-rata produksi relatif dinyatakan oleh persamaan berikut :

$$
\mathrm{t}, 0=\frac{1}{\mathrm{n}}\left[\sum \frac{\mathrm{q}_{\mathrm{t}}}{\mathrm{q}_{\mathrm{o}}} \times 100 \%\right]
$$

$\rightarrow \mathrm{n}$ adalah banyaknya jenis barang. 


\section{Indeks Agregatif}

- Indeks Agregatif merupakan indeks yang terdiri dari beberapa barang.

- Indeks Agregatif terdiri dari 2 bentuk, yaitu:

- Indeks Agregatif Tidak Tertimbang

- Indeks Agregatif Tertimbang 


\section{Indeks Agregatif Tidak Tertimbang}

- Indeks Agregatif tidak tertimbang digunakan untuk unit-unit yang mempunyai satuan yang sama .

- Indeks ini diperoleh dengan jalan membagi hasil penjumlahan harga pada waktu yang bersangkutan dengan hasil penjumlahan harga pada waktu dasar.

- Rumus Indeks Agregatif Tidak Tertimbang:

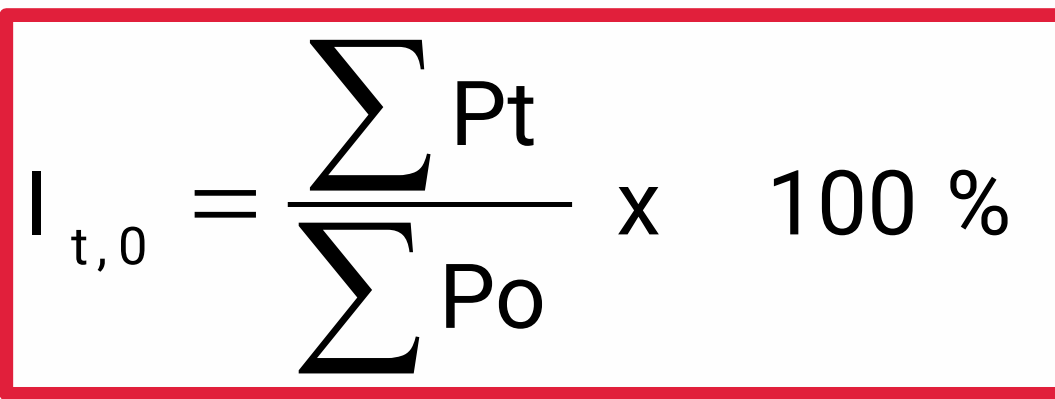




\section{Indeks Agregatif Tertimbang}

- Indeks agregatif tertimbang ialah indeks yang dalam pembuatannya telah dipertimbangkan faktor-faktor yang akan mempengaruhi naik turunnya angka indeks tersebut.

- Timbangan yang akan dipergunakan untuk pembuatan indeks biasanya :

1. Kepentingan relatif

2. Hal-hal yang ada hubungannya atau ada pengaruhnya terhadap naik turunnya indeks tersebut. 


\section{Indeks Harga Dan Produksi Agregatif Tertimbang}

Rumus yang digunakan:

1. Rumus Laspeyres

2. Rumus Paasche

3. Rumus Drobisch

4. Rumus Fisher

5. Rumus Marshal-Edgeworth 


\section{Rumus Laspeyres}

Indeks Harga Agregatif Tertimbang

$$
I L_{t, 0}=\frac{\sum p_{t} q_{0}}{\sum p_{0} q_{0}} \times 100 \%
$$

Indeks Produksi Agregatif Tertimbang

$$
I L_{t, 0}=\frac{\sum q_{t} p_{0}}{\sum q_{0} p_{0}} \times 100 \%
$$

$\mathrm{IL}=$ Indeks Laspeyres

$\mathrm{p}_{\mathrm{t}}=$ harga waktu $\mathrm{t}$

$\mathrm{p}_{0}=$ harga waktu 0

$\mathrm{q}_{\mathrm{t}}=$ produksi waktu 0

$\mathrm{q}_{0}=$ produksi waktu 0 


\section{Rumus Paasche}

Indeks Harga Agregatif Tertimbang

$$
I P_{t, 0}=\frac{\sum p_{t} q_{t}}{\sum p_{0} q_{t}} \times 100 \%
$$

Indeks Produksi Agregatif Tertimbang

$$
I P_{t, 0}=\frac{\sum q_{t} p_{t}}{\sum q_{0} p_{t}} \times 100 \%
$$




\section{Rumus Drobisch}

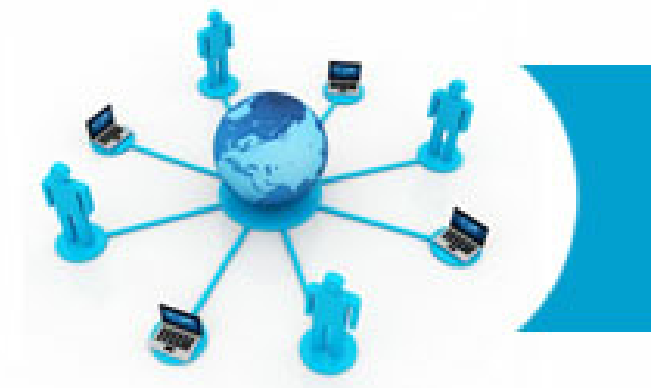

Indeks Harga dan Produksi Agregatif Tertimbang

$$
I D_{t, 0}=\frac{I L_{t, 0}+I P_{t, 0}}{2}
$$




\section{Rumus Fischer}

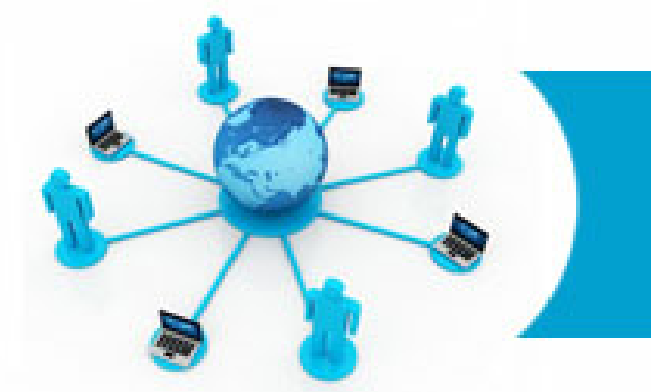

Indeks Harga dan Produksi Agregatif Tertimbang

$$
I F_{t, 0}=\sqrt{I L_{t, 0} \cdot I P_{t, 0}}
$$




\section{Rumus Marshal-Edgeworth}

Indeks Harga Agregatif Tertimbang

$$
\text { IME } t, 0=\frac{\Sigma\left[P_{t}\left(q_{0}+q_{t}\right)\right]}{\Sigma\left[P_{0}\left(q_{0}+q_{t}\right)\right]} \times 100
$$

Indeks Produksi Agregatif Tertimbang

$$
\text { IME } t, 0=\frac{\Sigma\left[q_{t}\left(P_{0}+P_{t}\right)\right]}{\Sigma\left[q_{0}\left(P_{0}+P_{t}\right)\right]} \times 100
$$




\section{Contoh Soal}

\begin{tabular}{|c|c|c|c|c|c|c|}
\hline \multirow{2}{*}{ Komoditas } & \multicolumn{3}{|c|}{ Harga } & \multicolumn{3}{c|}{ Produksi } \\
\cline { 2 - 7 } & 2008 & 2009 & 2010 & 2008 & 2009 & 2010 \\
\hline X & 200 & 300 & 300 & 300 & 400 & 500 \\
Y & 300 & 400 & 500 & 400 & 600 & 700 \\
Z & 500 & 500 & 600 & 400 & 700 & 800 \\
\hline
\end{tabular}

Tentukan indeks harga tertimbang dengan menggunakan rumus Laspeyres, Paasche, Drobisch, Fischer, dan Marshal Edgeworth

tahun 2010 dengan tahun dasar 2008! 


\section{Indeks Laspeyres}

\begin{tabular}{|c|c|c|c|c|c|c|c|c|}
\hline & \multicolumn{3}{|c|}{ Harga } & \multicolumn{3}{|c|}{ Produksi } & \multirow[b]{2}{*}{$p_{t} q_{0}$} & \multirow[b]{2}{*}{$p_{0 .} q_{0}$} \\
\hline & $2008\left(p_{0}\right)$ & 2009 & $2010\left(p_{t}\right)$ & $2008\left(q_{0}\right)$ & 2009 & 2010 & & \\
\hline $\mathrm{X}$ & 200 & 300 & 300 & 300 & 400 & 500 & 90000 & 60000 \\
\hline$Y$ & 300 & 400 & 500 & 400 & 600 & 700 & 200000 & 120000 \\
\hline Z & 500 & 500 & 600 & 400 & 700 & 800 & 240000 & 200000 \\
\hline$\Sigma$ & & & & & & & 530000 & 380000 \\
\hline
\end{tabular}

$\mathrm{IL}_{\mathrm{t}, 0}=\frac{\sum\left[\mathrm{p}_{\mathrm{t}} \mathrm{q}_{0}\right]}{\sum\left[\mathrm{p}_{0} \mathrm{q}_{0}\right]} \times 100 \%$

$\Rightarrow \quad \mathrm{LL}_{2010,2008}=\frac{530000}{380000} \times 100 \%=139,47 \%$

Page 20 


\section{Indeks Paasche}

\begin{tabular}{|c|c|c|c|c|c|c|c|c|}
\hline & \multicolumn{3}{|c|}{ Harga } & \multicolumn{3}{|c|}{ Produksi } & \multirow[b]{2}{*}{$p_{t} q_{t}$} & \multirow[b]{2}{*}{$p_{0 .} q_{t}$} \\
\hline & 2008(po) & 2009 & $2010(p t)$ & 2008 & 2009 & 2010(qt) & & \\
\hline$x$ & 200 & 300 & 300 & 300 & 400 & 500 & 150000 & 100000 \\
\hline$Y$ & 300 & 400 & 500 & 400 & 600 & 700 & 350000 & 210000 \\
\hline Z & 500 & 500 & 600 & 400 & 700 & 800 & 480000 & 400000 \\
\hline$\Sigma$ & & & & & & & 980000 & 710000 \\
\hline
\end{tabular}

$$
I P_{t, 0}=\frac{\Sigma\left[p_{t} q t\right]}{\Sigma\left[p_{0} q t\right]} \times 100 \%
$$

$$
c P_{t, 0}=\frac{980000}{710000} \times 100 \%=138,03 \%
$$




\section{Indeks Drobisch \& Fisher}

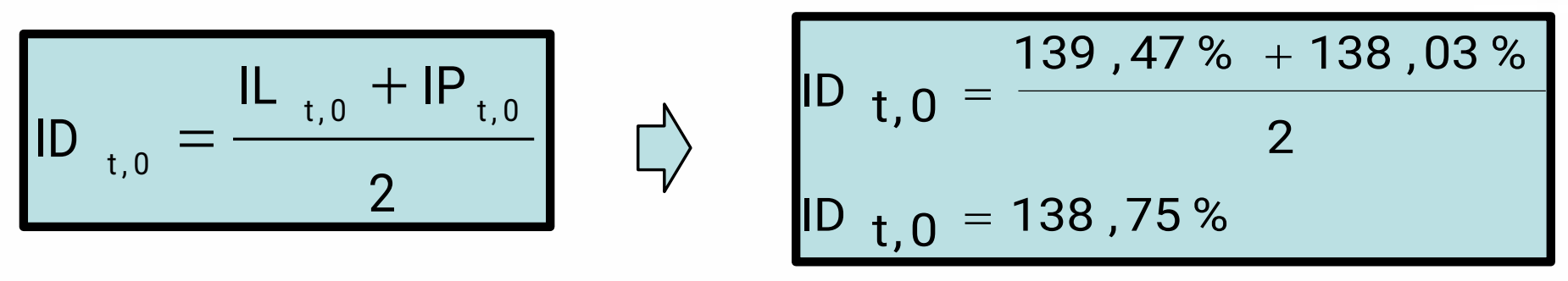

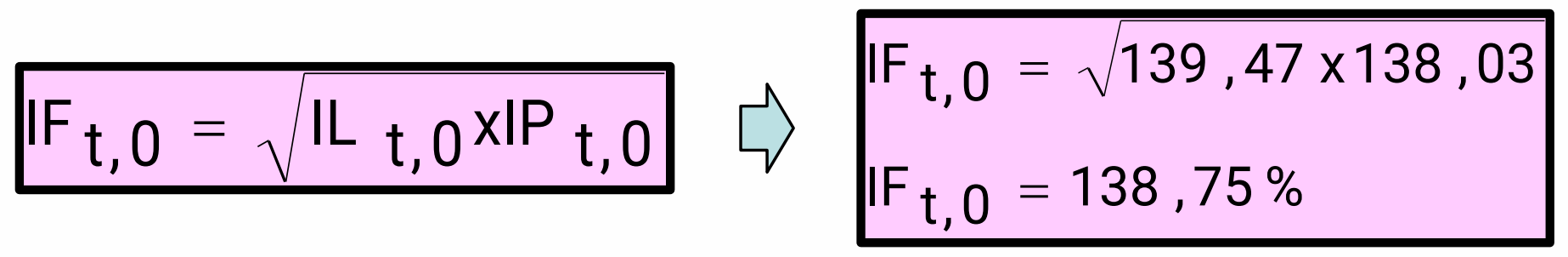




\section{Indeks Marshal-Edgeworth}

\section{Indeks Harga}

\begin{tabular}{|c|c|c|c|c|c|c|c|c|}
\hline & \multicolumn{3}{|c|}{ Harga } & \multicolumn{3}{|c|}{ Produksi } & \multirow{2}{*}{} \\
\cline { 2 - 7 } & $2008\left(p_{0}\right)$ & 2009 & $2010\left(p_{t}\right)$ & 2008(q) & 2009 & $2010(q t)$ & pt(q0+qt) & p0(q0+qt) \\
\hline$X$ & 200 & 300 & 300 & 300 & 400 & 500 & 240000 & 160000 \\
$Y$ & 300 & 400 & 500 & 400 & 600 & 700 & 550000 & 330000 \\
$Z$ & 500 & 500 & 600 & 400 & 700 & 800 & 720000 & 600000 \\
\hline$\Sigma$ & & & & & 1510000 & 1090000 \\
\hline
\end{tabular}

IME ${ }_{t, 0}=\frac{\sum\left[p_{t}\left(q_{0}+q_{t}\right)\right]}{\sum\left[p_{0}\left(q_{0}+q_{t}\right)\right]} \times 100 \%$

c) IME $\mathrm{t}, 0=\frac{1510000}{1090000} \times 100 \%=138,53 \%$ 


\section{Indeks Marshal-Edgeworth}

\section{Indeks Produksi}

\begin{tabular}{|c|c|c|c|c|c|c|c|c|}
\hline & \multicolumn{3}{|c|}{ Harga } & \multicolumn{3}{c|}{ Produksi } & \multirow{2}{*}{} \\
\cline { 2 - 7 } & $2008\left(p_{0}\right)$ & 2009 & $2010\left(p_{t}\right)$ & $2008\left(q_{0}\right)$ & 2009 & $2010(q t)$ & qt(p0+pt) & q0(p0+pt) \\
\hline$X$ & 200 & 300 & 300 & 300 & 400 & 500 & 250000 & 150000 \\
$Y$ & 300 & 400 & 500 & 400 & 600 & 700 & 560000 & 320000 \\
$Z$ & 500 & 500 & 600 & 400 & 700 & 800 & 880000 & 440000 \\
\hline$\Sigma$ & & & & & 1690000 & 910000 \\
\hline
\end{tabular}

$\operatorname{IME}{ }_{t, 0}=\frac{\sum\left[q_{t}\left(p_{o}+p_{t}\right)\right]}{\sum\left[q_{o}\left(p_{o}+p_{t}\right)\right]} \times 100 \%$

$\Rightarrow \quad$ IME ${ }_{\mathrm{t}, 0}=\frac{1690000}{9100000} \times 100 \%=185,71 \%$




\section{Hasil Studi Kasus}

Mengenai Perubahan Marga Pangan Per Tahun

- Indeks Tertimbang
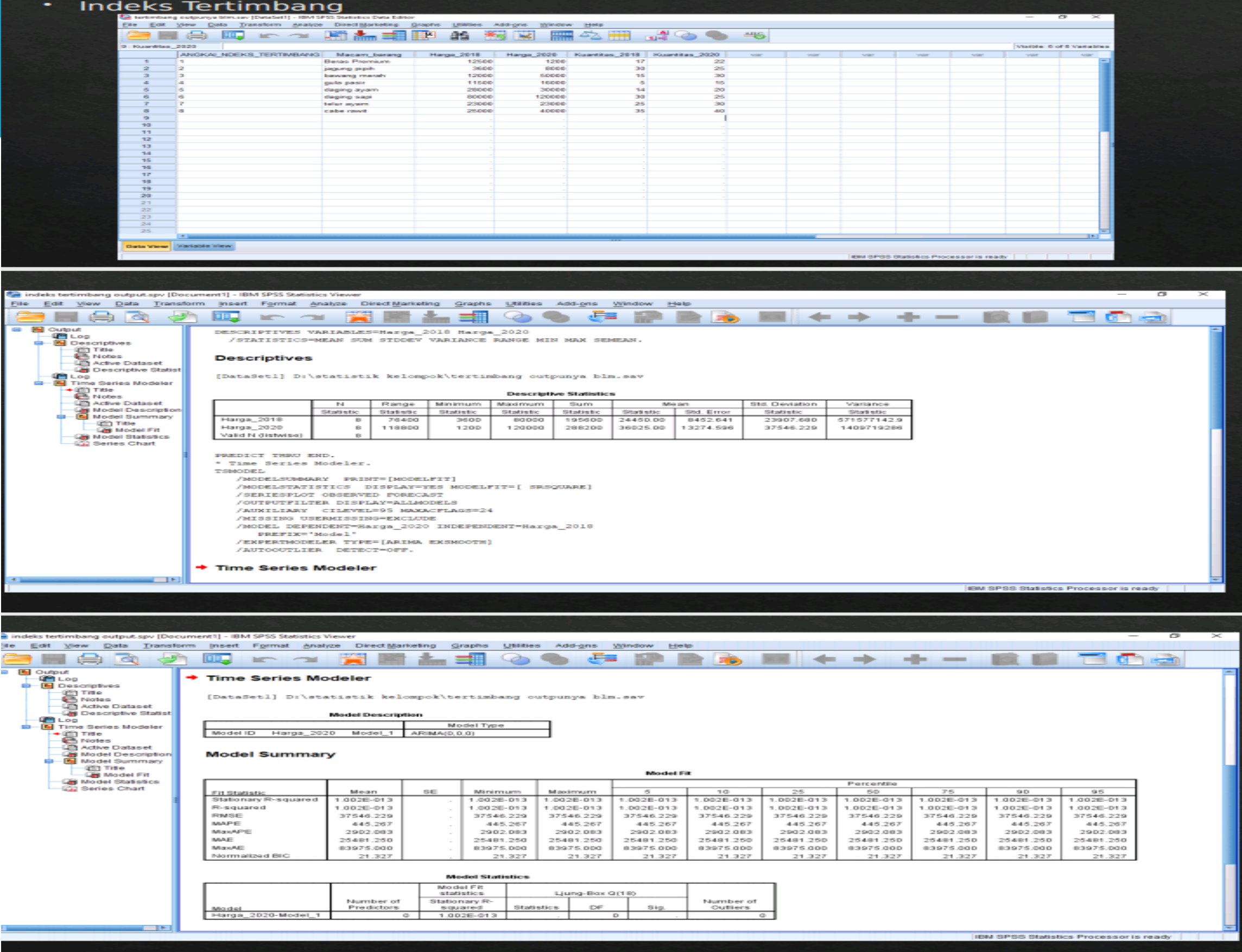

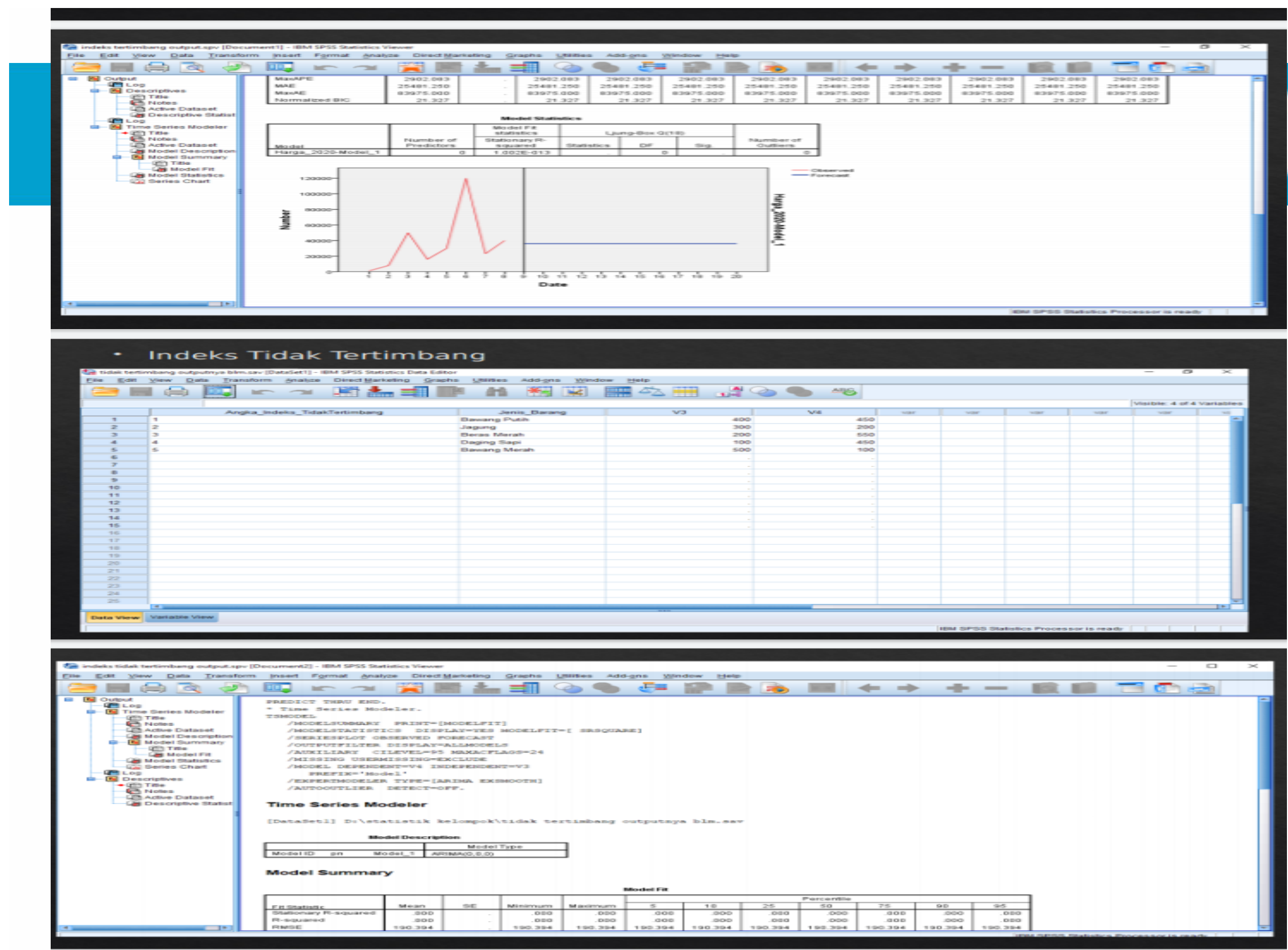

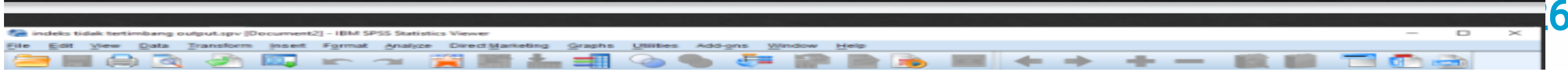




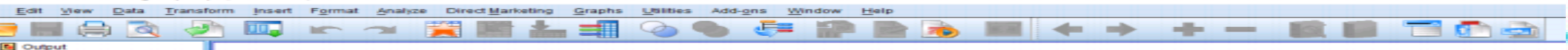

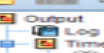

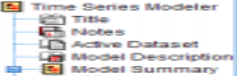

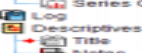

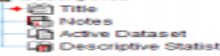

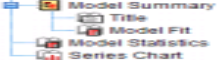
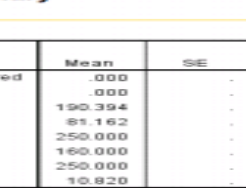

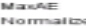

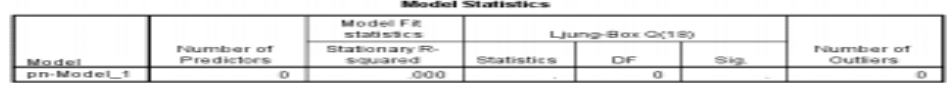

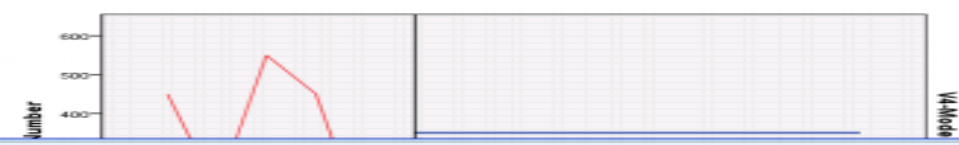

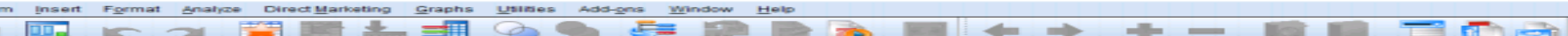

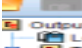

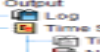

t.

ton

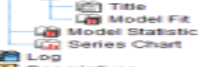

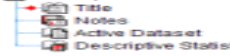

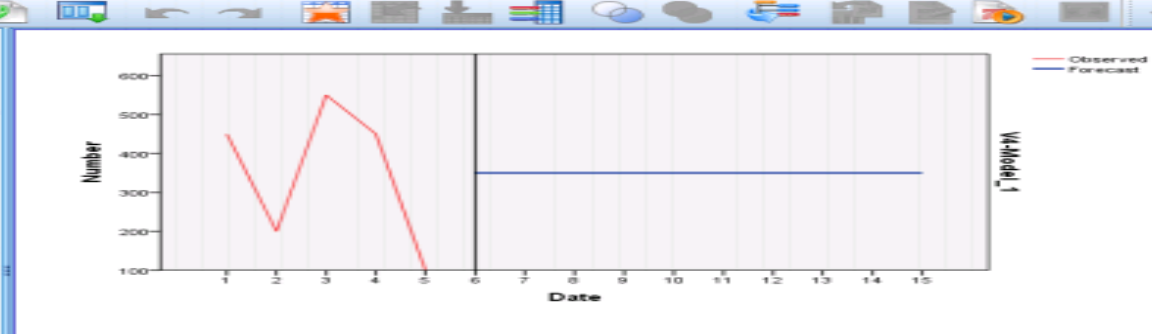

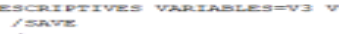

Descriptives

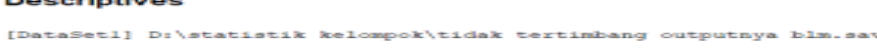

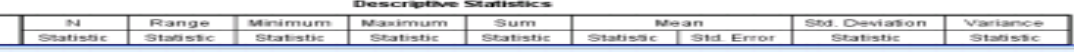

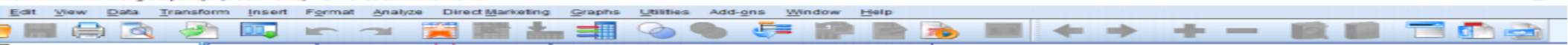

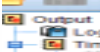

Trest

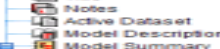

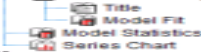

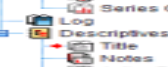

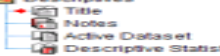

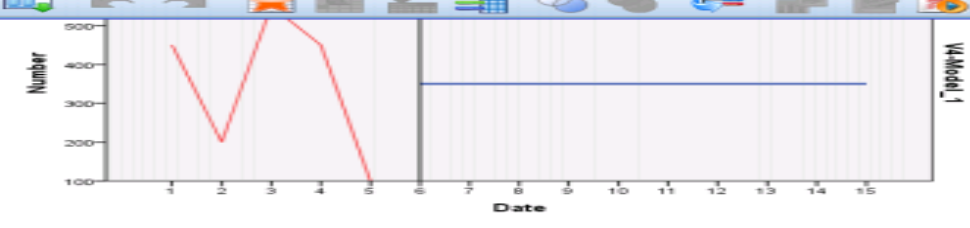

Tsave

Descriptives

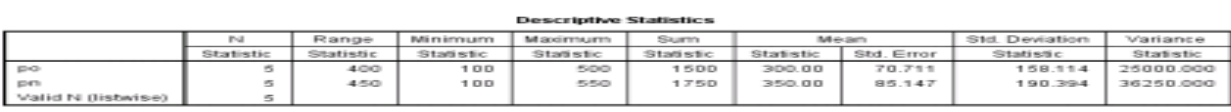

